\title{
De re bibliographica: BILEGA entre os recursos sobre o galego e o portugués na Internet
}

\author{
Francisco García Gondar \\ Universidade de Santiago de Compostela / CRPIH
}

\begin{abstract}
Resumo:
Neste traballo describo as principais características, contido e posibilidades de explotación da Bibliografía Informatizada da Lingua Galega (BILEGA), base de datos desenvolvida no Centro Ramón Piñeiro para a Investigación en Humanidades (CRPIH). Previamente, presento unha reflexión xeral sobre as vantaxes do formato dixital e a rede Internet para a construcción e difusión de fontes de información bibliográfica especializada, e ofrezo unha descrición sumaria dos recursos deste tipo que actualmente existen na Internet para o galego e o portugués. Estes recursos constitúen o contexto inmediato a partir do cal se deseñou e desenvolveu BILEGA.
\end{abstract}

Palabras chave:

Bibliografía, bases de datos, recursos en liña, galego, portugués.

\begin{abstract}
:
In this work I describe the main characteristics, content and possibilities of exploitation of the Bibliografía Informatizada da Lingua Galega (BILEGA), a database developed in the Centro Ramón Piñeiro para a Investigación en Humanidades (CRPIH). Before this, I put forward a general reflection on the advantages of the digital format and the Internet for the construction and diffusion of sources of specialized bibliographical information, and I offer a summary description of the resources of this type that at the moment exist on the Internet for Galician and Portuguese languages. These resources constitute the immediate background starting from which BILEGA was designed and developed.
\end{abstract}

Key words:

Bibliography, databases, online resources, Galician language, Portuguese language.

\section{A Internet e as bibliografías especializadas}

Unha consecuencia do extraordinario desenvolvemento das tecnoloxías da información e das telecomunicacións no último cuarto de século é a rede Internet. 
Malia a súa xuventude, constitúe un piar básico do que se coñece como sociedade da información: o seu rápido crecemento en contidos e en número de usuarios está a ter fondas repercusións nos modos de producción e difusión da información a nivel mundial; ademais, está destinada a modificar -en realidade, xa o está facendo- os nosos hábitos e formas de interacción ata extremos dificilmente imaxinables hoxe.

Unha das moitas tarefas de producción de información en que se vai facendo habitual recorrer ás novas tecnoloxías é a dos traballos de compilación bibliográfica. Dou por suposto que a utilidade das fontes de información bibliográfica en calquera campo de investigación -particularmente, na investigación filolóxica e lingüística- está hoxe máis que nunca garantida polo notorio incremento cuantitativo da producción científica e a imparable tendencia á globalización. Pero resulta igualmente claro que a calidade e a eficiencia destas fontes pode verse notablemente mellorada na medida en que se conciban e desenvolvan como recursos dixitais, tratando de sacarlles a máxima rendibilidade ás posibilidades de almacenamento estructurado e de recuperación rápida e precisa da información a partir dunha clasificación multidimensional das referencias bibliográficas (RB) que o dito formato permite con ferramentas como os xestores de bases de datos. Se a isto lle engadimos as posibilidades de actualización continua e de acceso a través da Internet, non parece arriscado afirmar que o futuro destes recursos non se atopa no libro impreso -que moi probablemente acabará abandonando este campo da actividade científica ou limitando moito a súa presencia nel-, senón no formato dixital.

As posibilidades que na actualidade ofrece este formato son enormes, debido ao continuo aumento da capacidade de almacenamento dos soportes e da velocidade de procesamento da información dixitalizada. Por outra banda, os xestores de bases de datos non deixaron de perfeccionarse ó longo das dúas últimas décadas e constrúense actualmente cun alto grao de modularidade. Isto significa que nos encontramos en inmellorables condicións para abordarmos o desenvolvemento de fontes de información bibliográfica especializada en formato dixital que melloren -en cantidade, calidade e actualidade da información- os catálogos automatizados das bibliotecas e mesmo as bibliografías publicadas ata hai pouco tempo exclusivamente en forma impresa.

Certamente, dentro do ámbito da xestión documental contamos xa cunha dilatada experiencia no uso de técnicas de almacenamento da información bibliográfica en formato dixital. En pouco máis dunha década asistimos á dixitalización da información sobre os fondos bibliográficos existentes nas bibliotecas de innumerables universidades e centros de investigación de todo o mundo (entre eles, as bibliotecas nacionais de moitos países) e, gracias á Internet, hoxe é posible acceder desde calquera lugar a esa información. Tamén vai normalizándose a publicación en for- 
mato dixital de bibliografías periódicas ${ }^{1}$ e están a desenvolverse interesantísimos proxectos de bibliografías especializadas ${ }^{2}$ co mesmo formato; en ambos os casos é xa bastante habitual que saian ao mercado en soporte CD-ROM e que ao mesmo tempo se ofreza acceso en liña a través da Internet.

Sen embargo, os catálogos automatizados das bibliotecas -imprescindibles hoxe para localizar axiña traballos do noso interese- están lonxe de cubriren as necesidades de información especializada dos que traballan nun ámbito concreto da actividade científica. Estas son, na miña opinión, algunhas das limitacións que presentan:

a) Da súa construcción e xestión encárganse especialistas en biblioteconomía e documentación que, agás no caso de bibliotecas moi especializadas, se ven obrigados a catalogar fondos pertencentes a ámbitos científicos moi diversos. Se o sistema de xestión bibliotecaria non dispón de mecanismos orientados a garantir a homoxeneidade dos valores introducidos para caracterizar as RB, é fácil que se produza disparidade de criterios na clasificación e que a RB do mesmo tipo (mesmo a distintas edicións dunha mesma obra) se lles asignen valores diferentes, o cal, evidentemente, repercute na precisión dos resultados que poden obterse nas interrogacións ao catálogo.

b) Soen seguir as normas estándar de catalogación, caracterizando as RB a partir da clasificación decimal universal (CDU), que resulta absolutamente insuficiente como clasificación especializada. É certo que esta clasificación permite expansións e que moitas bibliotecas utilizan un sistema enriquecido a partir da mesma; pero o problema destas expansións é que son realizadas habitualmente polos propios bibliotecarios, cun coñecemento bastante limitado dos aspectos máis relevantes ou máis novos dun campo científico, que son os que deberían incorporarse a unha clasificación máis detallada cá CDU, sobre todo se a súa finalidade é a de servir de instrumento para a recuperación de rexistros dunha base de datos bibliográfica (sexa un catálogo automatizado dunha biblioteca ou outro tipo de recurso).

c) Non é habitual que ofrezan información sobre o contido das publicacións periódicas e sobre os traballos incluídos en actas de reunións científicas (congresos, coloquios, xornadas, seminarios, etc.) ou como capítulos de monografías con autoría múltiple. Ben é certo que se editan en CD-ROM diversas bibliografías

1 No que se refire ao campo lingüístico, poden servir de exemplo a MLA International Bibliography, que ofrece RB sobre lingüística, literatura e folclore dende 1963, ou Linguistics and Language Behavior Abstracts (LLBA), que contén RB con resumos de artigos, teses de doutoramento, monografías e informes sobre investigacións no eido da conducta lingüística.

2 É o caso de PHILOBIBLON, base de datos biobibliográfica dos primeiros textos producidos na Península Ibérica á que me referirei no apartado 3.3. 
que baleiran sistematicamente este tipo de publicacións ${ }^{3}$ e que tamén empezan a aparecer na Internet bases de datos especializadas neste tipo de traballos ${ }^{4}$.

d) Cada documento ou rexistro do catálogo corresponde normalmente a un único asento bibliográfico, xa que a finalidade deste tipo de recurso é informar dos fondos existentes nunha biblioteca ou nunha agrupación de bibliotecas. Iso significa que para coñecer a historia editorial dun traballo (reedicións, edicións parciais, edicións facsimilares, traduccións, etc.) o usuario vese obrigado a consultar varios documentos. E aínda esa consulta non lle garante unha información completa, pois para iso é preciso que a biblioteca ou grupo de bibliotecas a que pertence o catálogo dispoñan nos seus fondos de todos os exemplares que forman parte desa historia.

e) Non soen ofrecer ningún tipo de anotación sobre o contido das RB, máis aló da que se poida deducir dos diferentes elementos utilizados na súa clasificación (descritores, identificadores, topónimos, referencias cronolóxicas e claves da CDU).

Unha bibliografía especializada en formato dixital -concibida como servicio de calidade a unha determinada comunidade de investigadores- debería tratar de superar estas limitacións e para iso sería necesario:

1) Determinar coa maior precisión posible o seu ámbito de competencia. É ben sabido que o grao de cobertura das fontes de información bibliográfica pode variar moito: ademais dos catálogos bibliotecarios, existen bibliografías temáticas, bibliografías selectivas, guías bibliográficas, bibliografías periódicas a partir de certa data, repertorios bibliográficos con pretensións de exhaustividade, etc. Os usuarios dunha fonte de información bibliográfica diferente a un catálogo dunha biblioteca deberían ter a posibilidade de coñecer coa máxima precisión os límites do mesmo para teren certa seguridade do que poden ou non achar nel.

2) Garantir un alto grao de actualidade. Unha das moitas vantaxes que ofrece o formato dixital e, particularmente, a estructura de base de datos é a posibilidade de concibir as fontes de información bibliográfica como proxectos abertos, sempre

3 É o caso, no noso país, da base de datos ISOC-Lengua y Literatura, elaborada polo Centro de Información e Documentación Científica (CINDOC) do Consello Superior de Investigacións Científicas, que recolle RB de artigos publicados dende 1975 en 150 revistas españolas de Lingüística e Literatura e 176 misceláneas; ademais inclúe actas de congresos e artigos de compilacións, aínda que non de forma exhaustiva. Este recurso tamén é accesible por Internet previa subscrición en $<$ http://www.cindoc.csic.es $>$.

4 En España son ben coñecidas a base de datos COMPLUDOC, da Biblioteca da Universidade Complutense de Madrid (<http://www.ucm.es/bucm/>), e a Base de dades de sumaris electrònics, do Consorcio de Bibliotecas Universitarias de Cataluña (<http://sumaris.cbuc.es/>). 
dispostos para seren actualizados a través da implementación individual de novos rexistros ou a través de cargas masivas de grupos de rexistros cada certo tempo. Un recurso que ofreza información actualizada posúe un valor engadido porque supera a limitación tradicional dunha bibliografía en forma impresa. Un catálogo automatizado ten ese valor adicional, pero en certo modo limitado porque unicamente informa dos fondos adquiridos pola biblioteca.

3) Enriquecer o repertorio de valores utilizados para caracterizar ou clasificar as RB coa finalidade de facilitar a localización precisa das que entran dentro do campo de interese do usuario. O camiño máis doado para acadar este obxectivo nun recurso bibliográfico dixital é establecer varios parámetros de clasificación que poidan utilizarse simultaneamente nas buscas. Téñase en conta que a estructuración dunha bibliografía en forma de base de datos abre posibilidades de organización da información impensables nun texto impreso ou na súa translación ao formato dixital e isto repercute directamente na potencia das buscas e na precisión dos resultados que se poden obter delas. Para aproveitar este tipo de organización nunha bibliografía filolóxica e/ou lingüística en formato dixital, cómpre introducir varios parámetros de clasificación metalingüística das RB como os que temos implementado en BILEGA (véxase 4.2.2).

4) Asociar asentos bibliográficos que estean relacionados. Nunha base de datos bibliográfica poden incluírse asentos bibliográficos ao estilo dun catálogo automatizado dunha biblioteca. Como xa sinalei, a característica fundamental da organización tipo catálogo é que cada asento corresponde normalmente a un rexistro da base de datos. Sen embargo, nunha bibliografía especializada xulgo moito máis pertinente a asociación de asentos bibliográficos relacionados, creando varias táboas que permitan facer explícitas esas relacións ou agrupándoos nun mesmo rexistro. Esta última é a solución adoptada en BILEGA a través da creación de rexistros que poden conter múltiples asentos bibliográficos, segundo veremos no 4.2.2.

5) Incluír algún tipo de anotación sobre o contido das RB, de xeito tal que se vexa enriquecido o índice correspondente ao campo da base de datos en que se introducen esas anotacións, creándose así outra vía para potenciar a especificidade das buscas. Na súa forma ideal, unha bibliografía especializada debería incluír nesas anotacións algún tipo de apreciación crítica sobre a calidade das RB comentadas.

Son varias, pois, as dimensións en que se pode actuar para mellorar a calidade destes recursos e a unha boa parte delas prestamos especial atención no momento de deseñar a base de datos que motiva este artigo. Pero, antes de presentar as súas características, repasarei as principais fontes de información bibliográfica sobre o galego e o portugués que neste momento se poden achar na rede. 


\section{As fontes de información bibliográfica sobre o galego na Internet $^{5}$}

2.1. Antes da década de 1970 a presencia do galego moderno nos repertorios bibliográficos impresos de carácter nacional ou internacional era máis ben testemuñal. A súa nula promoción social e, como consecuencia dela, a inexistencia dunha tradición de estudios minimamente consolidada xogaban en contra desa presencia.

- No ámbito nacional, dúas revistas filolóxicas de prestixio incluíron dende finais da década de 1950 nos seus apéndices bibliográficos periódicos algunhas entradas bibliográficas sobre o galego: a Revista de Filología Española a partir do tomo 41 (1957), nunha sección titulada "Gallego-portugués", e a Revista de Dialectología y Tradiciones Populares a partir do tomo 14 (1958), nunha sección de idéntico nome que, dende o tomo 16 (1960), pasaría a chamarse "Gallego, portugués y brasileño".

- Moito máis relevantes foron os apéndices bibliográficos que -por iniciativa do ilustre polígrafo Xosé Fernando Filgueira Valverde- se publicaron co título de "Bibliografía de Galicia" nos Cuadernos de Estudios Gallegos desde o seu primeiro número (1944). Malia non ser unha bibliografía exclusivamente lingüística nin estar dedicada só a traballos sobre a cultura galega, o certo é que as 33 entregas publicadas entre 1944-1987 (as dúas últimas como monografías independentes correspondentes aos anos 1982 e 1983) constituíron a fonte de información máis completa sobre a lingüística e a filoloxía galega que se facía entón.

- No ámbito das bibliografías periódicas de carácter internacional, a única excepción que se pode salientar con anterioridade a 1975 é a Romanische Bibliographie, que se publica anualmente como suplemento da revista Zeitschrift für Romanische Philologie e que aínda hoxe segue a ser a máis completa e prestixiosa bibliografía periódica de romanística. Neste repertorio vénse reservando un apartado específico para o galego -integrado dentro da sección dedicada á dialectoloxía portuguesa - xa dende a entrega correspondente aos anos 1940-1950 (RB 1957). Ata hai pouco tempo era o repertorio bibliográfico internacional que ofrecía máis información sobre o galego moderno, aínda cando esa información (sobre todo a relativa aos últimos dez ou quince anos) estivese lonxe de ser completa. No ano 2002 acaban de publicarse en CD-ROM as entregas correspondentes aos anos 1997-2000, de tal xeito que a través dunha biblioteca que ofreza o servicio de acceso en liña sería posible consultalas por Internet.

5 Todas as referencias a páxinas da Internet ou a rexistros e datos globais de BILEGA que se citan ao longo do artigo foron comprobadas por última vez mediante a pertinente consulta o 15/05/2003. 
2.2. A situación comezou a cambiar na década de 1980. O proceso de institucionalización da lingüística galega iniciado na década anterior acabaría reflectíndose nestes repertorios bibliográficos que, ao longo das décadas de 1980 e 1990, foron introducindo un apartado específico -diferenciado do que tradicionalmente se dedicara ao portugués ou incluído dentro del- para a información bibliográfica sobre a lingua galega.

- Así, na bibliografía anual publicada polo Comité International Permanent des Linguistes (Bibliographie linguistique de l'année [...] et complément des années précédentes $=$ Linguistic Bibliography for the Year [...] and Supplement for Previous Years) menciónase por primeira vez o galego, a carón do portugués ("Portugais et galicien = Portuguese and Galician"), na entrega correspondente ao ano 1975 (BL 1978). Pero ata a do ano 1987 (BL 1989) non atopamos unha sección especificamente dedicada ao galego moderno e diferenciada da que se viña reservando para o galego-portugués medieval. A información desta nova sección titulada "Galicien moderne = Modern Galician" mellorou notablemente a partir do volume publicado en 1996 (que recolle os traballos aparecidos en 1993); se ata entón se responsabilizaran dela profesores de universidades norteamericanas (cos atrancos que implica a distancia para acadar a información), dende esa entrega participa como colaborador Xosé Luís Regueira Fernández, profesor de Filoloxía Galega da Universidade de Santiago de Compostela que nos últimos anos se ven dedicando a tarefas de compilación da bibliografía lingüística galega. Dende 2002 está operativa na URL $<$ http://www.kb.nl/kb/blonline/blonline.html> a base de datos BL ONLINE, que constitúe a versión electrónica da publicación impresa; na actualidade contén todas as entradas dos volumes impresos correspondentes aos anos 1993-1998 e segue a incrementarse con entradas posteriores a 1998. Os usuarios teñen a posibilidade de introducir no formulario correspondente valores de busca (por exemplo, 'Galician language') que lles permitirán localizar especificamente os rexistros bibliográficos que nalgún dos seus campos inclúan valores idénticos aos elixidos.

- A bibliografía de romanística que se publica anualmente nos Estados Unidos na revista Comparative Romance Linguistics Newsletter incluíu por primeira vez unha sección específica para o galego no número 37/2 con traballos publicados entre 1980-1987 (Freire 1988). Esta nova sección, que non se mantivo de forma constante (entre 1988 e 1999 publicouse cinco veces), ofrecía unha información bastante incompleta, se temos en conta o grao de desenvolvemento que xa entón acadara a lingüística galega. A partir da entrega publicada en 2000, a información sobre o galego mellorou notablemente, xa que dende esa data pasou a responsabilizarse da redacción desa sección Xosé Luís Regueira Fernández. Este repertorio segue a publicarse en forma impresa, pero tamén se pode consultar de balde 
pola rede en <http://www.csdl.tamu.edu/ crln/>. O seu maior inconveniente é que cada entrega está gardada en forma de arquivo de texto independente (nas últimas, en formato PDF), de tal xeito que non é posible consultar conxuntamente información de distintas entregas (por exemplo, todos os traballos sobre o galego), nin tampouco realizar buscas selectivas mediante a introducción polo usuario de valores de busca específicos.

- A nivel nacional, a fonte de información bibliográfica máis salientable é a compilación realizada por un grupo de investigadores do Instituto da Lingua Galega, que apareceu inicialmente en varias entregas publicadas entre 1990 e 1992 na revista Cadernos de Lingua. O conxunto deste material bibliográfico, ao que se engadiu a información posterior a 1992, converteuse nunha monografía cunhas 2.500 entradas (Regueira 1996), concibida como guía orientativa e non como un repertorio exhaustivo. Posteriormente unha selección desta guía quedaría almacenada con formato de arquivo de texto nas páxinas do Instituto da Lingua Galega. Ata o momento actual, constitúe unha bibliografía pechada que recolle traballos publicados ata 1995 e que se pode consultar de balde na URL $<$ http://www.usc.es/ ilgas/Biblio00.html>.

- Mário J. Herrero Valeiro incluíu na rede en 1997 as RB sobre traballos de investigación e opinión de temática sociolingüística que reunira na súa Memoria de Licenciatura (Herrero Valeiro 1993) e que seguiu actualizando ata o momento de confeccionar a páxina. Este conxunto de asentos bibliográficos -que non pretende acadar a exhaustividade, sobre todo no referente a artigos de xornal- constitúe o que o autor chama Bibliografia de discurso glotopolítico na Galiza, á que se pode acceder de balde en <http://www.udc.es/dep/lx/mhv/bibglot.html>. O documento é un arquivo de texto en formato WordPerfect 5.2 para Windows que se pode importar ao ordenador propio.

- Tamén se poden encontrar algunhas orientacións bibliográficas en formato de texto sobre materiais para a aprendizaxe do galego en $<$ http://galego.org/biblioteca.html>.

- Pola súa banda, o Servicio de Normalización Lingüística da Universidade de Santiago de Compostela ofrece unha listaxe de obras lexicográficas (diccionarios e vocabularios monolingües e bilingües) e textos gramaticais de referencia en $<$ http://www.usc.es/ snlus/listabib.htm>. Algúns dos traballos lexicográficos que se citan nesta páxina poden consultarse en formato de texto, non permitindo outra navegación cá correspondente ás letras do abecedario.

- Por último, entre as iniciativas bibliotecarias creo que merece ser salientada a sección "Galicia" do catálogo automatizado da Biblioteca da Universidade de Santiago de Compostela. Esta sección acolle as publicacións de investigadores 
galegos ou foráneos, pero que traballan ou traballaron en Galicia. Verbo das publicacións filolóxico-lingüísticas, malia non ser un catálogo dedicado exclusivamente á lingua galega, ten a virtude de ofrecer información sobre traballos aparecidos en publicacións periódicas ou como capítulos de monografías, cousa que habitualmente non fan a maioría dos catálogos doutras bibliotecas.

En conclusión, non se pode dicir que sexan moitos os recursos bibliográficos sobre o galego que atopamos na rede; sen embargo, tendo en conta o aínda limitado número de traballos que conforman a tradición filolóxico-linguística galega desde os inicios da súa institucionalización, a información que ofrecen en conxunto é bastante completa. O que quizais se bota de menos é un recurso que ofreza unha información ampla (no sentido de abranguer todas as áreas da investigación lingüística e filolóxico-lingüística) e, ao mesmo tempo, actualizada; esta é precisamente a lagoa que trata de encher a Bibliografía Informatizada da Lingua Galega (BILEGA) a que me referirei no apartado 4.

\section{As fontes de información bibliográfica sobre o portugués na Internet}

3.1. Se veño de deixar constancia da recente presencia do galego nalgúns dos principais repertorios internacionais de bibliografía filolóxica e lingüística, a do portugués é moito máis antiga debido ao seu diferente estatus no ámbito da romanística xa dende os traballos fundacionais do século XIX. A súa presencia na clasificación canónica tradicional das linguas románicas e o desenvolvemento da filoloxía portuguesa no tránsito entre o século XIX e o XX foron elementos dabondo para garantir a atención a esta lingua nas fontes de información bibliográfica.

Moi diferente é a situación do portugués no que se refire aos recursos bibliográficos en formato dixital e, particularmente, aos que se poden achar na rede. Naturalmente, deben terse en conta como fontes importantes de información o Catálogo da

Biblioteca Nacional de Lisboa (PORBASE), que xa leva funcionando algúns anos e ao que se pode acceder en <http://sirius.bn.pt/sirius/sirius.exe >, e os catálogos das bibliotecas das distintas universidades portuguesas e brasileiras, boa parte deles creados nos últimos cinco ou seis anos. Pero só moi recentemente xurdiron en Portugal varias iniciativas dirixidas ao deseño e desenvolvemento de recursos dixitais de información bibliográfica sobre esta lingua, tratando así de superar a principal eiva que presentan na súa forma impresa tradicional: a rápida desactualización. Ofrezo a continuación unha descrición sumaria dos mesmos:

- Na Faculdade de Ciências Sociais e Humanas da Universidade Nova de Lisboa a Liña de Investigación $n^{\circ} 4$ (Lingüística Histórica), que dirixe António Henrique 
de Albuquerque Emiliano, estableceu como unha das súas prioridades a elaboración de bibliografías especializadas de Lingüística Histórica e Historia das Linguas. O primeiro proxecto deste tipo que na actualidade están a desenvolver algúns dos investigadores que integran esta liña é a Bibliografia de História da Língua Portuguesa (BHLP), concibida como base de datos que trata de constituírse nun repositorio o máis exhaustivo, actualizado e actualizable posible dos traballos diacrónicos sobre o portugués, e que terá como canle de difusión a rede Internet. Ata o momento recompilaron xa algúns materiais bibliográficos (unhas $400 \mathrm{RB}$, segundo a última información que figura na páxina web) e atópanse na fase de deseño da base de datos, de tal xeito que aínda non é posible acceder aos rexistros. Pode encontrarse información sobre este proxecto na URL $<$ http://www.fcsh.unl.pt/clunl/linha4.html>.

- O Centro de Linguística da Universidade de Lisboa (CLUL) inclúe entre os seus proxectos a elaboración dunha Bibliografia da Prosa Medieval em Língua Portuguesa baixo a responsabilidade de Isabel Vilares Cepeda. O seu obxectivo é ofrecer aos estudiosos da Idade Media información bibliográfica o máis actualizada posible sobre os textos medievais en prosa escritos en portugués. Esta investigación reflectiuse inicialmente nunha monografía impresa (Cepeda 1995) que agora se trata de actualizar con novas entradas. Pode atoparse información sobre este proxecto, do que aínda non é posible consultar resultados concretos a través da rede, en <http://www.clul.pt/sectores/projecto_bibliografia_prosa.html>.

- No Centro de Estudos de Lingüística Geral e Aplicada (CELGA) da Faculdade de Letras da Universidade de Coimbra iniciouse en setembro de 2001 un Projecto de Bibliografia Corrente de Linguística do Português, do que son responsables Ana Cristina Macário Lopes (como coordinadora), Graça Maria Rio-Torto e Cristina Martins. Esta bibliografía aspira a recoller nunha base de datos actualizable e accesible por Internet todas as RB sobre a lingua portuguesa publicadas en Portugal a partir do ano 2000. Despois da fase inicial de identificación das fontes de información bibliográfica que cumpría consultar e de deseño da base de datos, xunto co sistema de clasificación das RB, comezouse a construír en febreiro de 2002 e na actualidade xa é posible acceder vía web á información das RB incluídas. A concepción desta bibliografía é semellante á dun catálogo de biblioteca, xa que a información que ofrecen as fichas bibliográficas se limita aos datos relevantes desde o punto de vista biblioteconómico, non incluíndo nin resumos do contido dos traballos nin información sobre recensións ou notas de publicación. Pode verse información sobre este proxecto na páxina web <http://www.uc.pt/celga/proj_bclp.htm>, que tamén ofrece unha ligazón para a consulta da base de datos. Ademais desta posibilidade de consulta, anúnciase neste lugar un sistema de difusión selectiva da información a través do correo electrónico que aínda non está operativo. 
Nos tres proxectos está previsto acoller traballos dedicados á fase común galegoportuguesa e, polo tanto, constitúen investigacións relevantes tamén para o galego que contribuirán a fornecer información actualizada, sobre todo, da producción científica procedente de Portugal (e quizáis tamén do Brasil, país do que aínda non resulta fácil acadar información posta ao día e exhaustiva). Cos responsables do proxecto de Bibliografia de História da Língua Portuguesa o equipo de BILEGA xa estableceu un acordo inicial de colaboración para o intercambio de información, e está tamén en fase avanzada a negociación para un acordo do mesmo tipo cos responsables do proxecto de Bibliografia Corrente de Linguística do Português.

3.2. Fóra de Portugal, tamén existe algunha iniciativa para ofrecer información bibliográfica a través da rede. Concretamente, en Alemaña, no Portugalzentrum (Centro de Documentación sobre Portugal da Universidade de Tréveris), fundado en 1991, están a desenvolverse dúas bases de datos que se anuncian como accesibles en liña proximamente. A primeira (PORBPZ) acolle as entradas bibliográficas (polo momento, só obras existentes na biblioteca do Centro) fundamentalmente referidas a Portugal (en menor medida ás ex-colonias portuguesas, aínda que está prevista a expansión a todo o mundo lusófono); non é unha bibliografía especificamente lingüística, pois acolle traballos de diferentes ámbitos disciplinares (incluídos os estudios literarios), e neste momento conta con máis de 7.000 entradas. A segunda base de datos (polo momento, sen acrónimo) contén artigos sobre Portugal publicados en revistas científicas en lingua alemá (nunha primeira fase, artigos de lingüística e literatura); conta actualmente con 1.011 entradas. A URL de acceso ao Portugalzentrum é <http://www.unitrier.de/uni/foreinr/portugal/pagina1.htm>.

3.3. Malia constituíren repertorios bibliográficos especificamente dedicados aos textos medievais e aos estudios sobre os mesmos, aínda deben citarse aquí outros dous recursos importantes tanto para o galego como para o portugués, pois fornecen información bibliográfica sobre traballos lingüísticos ou filolóxicolingüísticos:

- A Bibliografia de Textos Antigos Galegos e Portugueses (BITAGAP) é unha base de datos que ofrece un catálogo unificado de todos os textos orixinariamente escritos en galego-portugués, galego e portugués, ou vertidos a estas linguas durante a Idade Media (ata comezos do século XVI). Inclúe un apartado de bibliografía secundaria (segundo os seus autores, non exhaustiva), que recolle RB de interese directo para as descricións, localizacións ou edicións dos manuscritos e das primeiras impresións dos textos. É nesta sección da base de datos onde se poden atopar traballos de interese lingüístico. BITAGAP foi concibida como un proxecto aberto, iniciado en 1988 por Arthur L.-F. Askins, Harvey L. Sharrer, Aida 
Fernanda Dias e Martha E. Schaffer e destinado a difundirse en versións electrónicas e, eventualmente, en formato impreso. Actualmente existen versións en CDROM e unha versión (menos completa cá do CD-ROM) de acceso gratuíto por Internet en $<\mathrm{http}$ ://sunsite.lib.berkeley.edu/PhiloBiblon//phhm.html>. Forma parte dun proxecto máis amplo (PHILOBIBLON), dirixido por Charles B. Faulhaber, no que se integra con outras dúas bases de datos: Bibliografía Española de Textos Antiguos (BETA) e Bibliografia de Textos Catalans Antics (BITECA). As tres poden ser consultadas conxuntamente ou por separado. Na miña opinión, constitúe un proxecto de grandísimo valor porque, ademais do rigor e minuciosidade da información que ofrecen as RB, no seu deseño aproveitouse toda a potencia e a versatilidade que caracteriza as bases de datos relacionais para acadar unha estructura con múltiples elementos de información ligados entre sí.

- O Boletín bibliográfico da Asociación Hispánica de Literatura Medieval acolle RB de traballos de edición e de análise de textos literarios e non literarios da Idade Media, así como algúns estudios lingüísticos e estudios de tipo histórico. Empezou a publicarse en forma impresa en 1987 e aparece habitualmente organizado en seccións independentes para cada unha das tradicións literarias hispánicas ${ }^{6}$. Unha destas seccións está dedicada, loxicamente, á literatura galego-portuguesa e dela xa se publicaron quince entregas, ofrecendo as máis recentes información sobre o contido dos traballos, aínda que non de forma exhaustiva. Neste momento é accesible por Internet en <http://griso.cti.unav.es/medieval/ahlm/Buscar.html>, pero a estructura que presenta o formulario de buscas é excesivamente sinxela, de tal xeito que non permite recuperar con certo grao de precisión a rica información que conteñen as RB.

\section{A Bibliografía Informatizada da Lingua Galega (BILEGA)}

\subsection{O proxecto}

No contexto que acabo de describir nos apartados 2 e 3 nace a Bibliografía Informatizada da Lingua Galega (BILEGA) como un dos proxectos iniciais do Centro Ramón Piñeiro para a Investigación en Humanidades (CRPIH), creado pola Xunta de Galicia en novembro de 1993.

BILEGA é una base de datos deseñada para ofrecer a través da Internet información bibliográfica exhaustiva, actualizada e actualizable sobre os traballos de investigación, divulgación e opinión dedicados á lingua galega en calquera das fases do seu

6 Ata a entrega 14 as tradicións galega e portuguesa aparecían agrupadas nunha mesma sección ("Literatura galaico-portuguesa"), pero, sorprendentemente, na entrega 15 (a última publicada ata agora) dedícase unha sección á literatura galega e outra á literatura portuguesa, o cal obriga a incluír dúas veces algunhas RB. 
desenvolvemento histórico, incluído o período prerromance. Foi inicialmente concibida como recurso de información dirixido exclusivamente a investigadores, pero, polo feito de acoller traballos de divulgación, cremos que tamén pode resultar útil para outras persoas que, dende distintos ámbitos de actividade profesional e con motivacións diferentes á investigación, poidan ter interese en dispoñer dalgún tipo de información sobre a lingua galega.

Poucos meses despois da creación do CRPIH, Guillermo Rojo e mais eu iniciabamos os traballos de deseño da base de datos a partir da experiencia que adquiriramos na construcción dunha base de datos bibliográfica no Departamento de Lingua Española da Universidade de Santiago de Compostela e mais na preparación da Bibliografía lingüística española que un grupo de profesores dese Departamento publicamos en varias entregas entre 1986 e 1993 na Revista de la Sociedad Española de Lingüística. Establecida a estructura de BILEGA, os aspectos formais da cita bibliográfica e mais os tesauros de temas, variedades de lingua e ámbitos (véxase 4.2.2), un equipo de bolseiras do CRPIH comezou a buscar e introducir RB na base de datos?

Os primeiros resultados do proxecto viron a luz nunha monografía impresa (García Gondar (dir.) 1995) que ofrecía, clasificadas por temas, algo máis de 5.000 entradas bibliográficas correspondentes ao material compilado no primeiro ano de traballo (entre maio de 1994 e xullo de 1995). Era un repertorio bibliográfico elaborado fundamentalmente a partir da consulta doutras fontes de información e isto fixo que se perpetuasen nel moitos erros procedentes desas fontes; ademais, como sospeitabamos, faltaban aínda bastantes RB e o seu nivel de anotación era moi baixo.

Estas eivas fixeron que nos tres anos seguintes (1996-1998) centrasemos os nosos esforzos na actualización retrospectiva e prospectiva de BILEGA, na revisión -mediante a consulta directa dos traballos- de todos os datos bibliográficos implementados previamente e na elaboración dun resumo dos mesmos, así como nos traballos de preparación do contorno para a súa xestión na Internet ${ }^{8}$.

\footnotetext{
7 O equipo inicial estivo formado por Ma Teresa Araújo García (1994-2001), Inés Diz Gamallo (1994-2001), Ma Teresa Monteagudo Cabaleiro (1994-1998) e Pilar Vázquez Grandas (1994-1998). A elas uniríanse posteriormente Eva Domínguez Noya (1995-2001) e Susana García Rodríguez (1997-2000). Actualmente traballan en BILEGA Cristina Blanco González (2001-...) e Déborah González Martínez (2002-...). Como director de BILEGA, a todas elas quero expresar dende estas páxinas o meu profundo agradecemento polo extraordinario entusiasmo e dedicación que sempre amosaron nas ingratas tarefas de busca bibliográfica. Tendo en conta que houberon de compatibilizar esas tarefas cos traballos de construcción do Corpus de Referencia do Galego Actual (CORGA), a súa dedicación resulta aínda máis meritoria.

8 Foi esta unha fase de estreita colaboración cos técnicos do Departamento de informática do CRPIH (Fernando Magán Muñoz, Jesús Rodríguez Castro e José Carlos Sánchez Rivas). Vaia para eles tamén a miña expresión de agradecemento, pois foron os responsables fundamentais de moitas das decisións que houbo que adoptar.
} 
A mediados de 1998 iniciabamos as probas de funcionamento de BILEGA (versión 1.0) na Internet, producíndose a súa inauguración oficial na rede o 12 de novembro dese ano. A base de datos contaba entón con 7.969 rexistros.

Dende ese momento BILEGA non deixou de medrar ata hoxe consonte o obxectivo de mantela o máis actualizada posible. Ademais das modificacións en rexistros antigos (corrección de erros, datos de novas edicións, traduccións, recensións, información sobre o contido), en xaneiro de 1999 cargáronse 574 rexistros novos (versión 1.0.1), en maio de 2000 outros 1.147 (versión 1.0.2) e, a partir de entón, tomamos a decisión de introducir individualmente os novos rexistros; unicamente na última fase deste período (desde novembro de 2002) paralizamos esta estratexia para preparar a versión 2.0, que será a que estea operativa cando se publiquen estas páxinas. A URL desta nova versión é a seguinte: <http://www.cirp.es/bdo/bil/bilega.html>.

\subsection{Estructura}

4.2.1. A creación da versión 2.0 de BILEGA vén motivada polo cambio do xestor que goberna o seu funcionamento9. Este cambio supón algunhas modificacións no sistema de buscas, pero a estructura de BILEGA v2.0 segue a ser idéntica á das versións 1.0, agás a desaparición dos campos multivaluados (é dicir, campos que poden almacenar máis dun valor) e dalgunha modificación na orde de presentación dos campos no formulario de buscas.

Esta estructura é máis ben simple desde o punto de vista informático, pois o que priorizamos no seu deseño foi a comodidade de acceso do usuario aos documentos, concibidos como unha especie de arquivos de texto estructurados que tratan de ofrecer a historia editorial completa de cada RB; deste xeito, un rexistro de BILEGA pode chegar a conter máis de dúas ducias de asentos bibliográficos (varias edicións do traballo, outros traballos derivados do primeiro que poden atoparse como rexistros distintos na mesma base de datos, traduccións, recensións, notas de publicación, ademais da información sobre o contido e de varias caracterizacións metalingüísticas que producen unha clasificación moi detallada da RB co obxectivo de facilitar a súa localización a través de múltiples parámetros de busca (máis aló da localización por autor, título ou ano de publicación). A clasificación temática das RB mesmo inclúe valores que, sen seren exactamente idénticos, amosan un certo grao de redundancia co obxectivo de facilitar varios camiños para a localización das RB segundo este parámetro metalingüístico.

9 As versións 1.0 de BILEGA foron xestionadas con BASISplus (pode atoparse información sobre este sistema en $<\mathrm{http} / / / \mathrm{www} .0 p e n t e x t . c o m /$ bais/>). O xestor que agora entra en funcionamento para BILEGA v2.0 é Oracle 9i SE Database (véxase información sobre o mesmo en <http://www.oracle.com/ip/deploy/database/oracle $9 \mathrm{i} />)$. 
BILEGA está organizada en dúas táboas:

a) A táboa BILEGA que contén todos os elementos de información sobre as RB.

b) A táboa REVISTAS que almacena os datos sobre as publicacións periódicas (revistas, semanarios, xornais) citadas na primeira táboa. Tamén se pode encontrar información sobre estas publicacións na sección de documentación da páxina web de BILEGA, nun arquivo de texto que ofrece unha listaxe coa forma en que se citan nos rexistros da táboa BILEGA, o título e o lugar de publicación. Na táboa REVISTAS pódense consultar outros datos como ISSN, Depósito Legal, cronoloxía da publicación, editorial ou institución editora e notas sobre a súa historia editorial.

É posible navegar dunha taboa á outra gracias á organización en marcos da páxina da base de datos: por exemplo, na consulta dun rexistro da táboa BILEGA un usuario quere dispoñer de datos sobre unha publicación periódica citada nese rexistro; para iso non ten máis que ir ao marco da esquerda da páxina e premer na táboa REVISTAS para localizar nela o rexistro correspondente a esa publicación.

Por razóns de espacio, limitareime a presentar a estructura da táboa BILEGA na versión 2.0, indicando cun signo “+” aqueles campos que posúen tesauro ${ }^{10}$ :

\begin{tabular}{|c|c|c|c|}
\hline & Campos & Seccións & Tesauro \\
\hline 1 & ID & - & - \\
\hline 2 & Título & - & - \\
\hline 3 & Autor & - & - \\
\hline 4 & Ano publicación & - & - \\
\hline 5 & Tema & - & + \\
\hline 6 & Enfoque & - & - \\
\hline 7 & Período & - & - \\
\hline 8 & Variedade lingua & - & + \\
\hline 9 & Ámbito & - & + \\
\hline 10 & Tipo traballo & - & - \\
\hline 11 & Data actualización & - & - \\
\hline 12 & Lingua documento & - & - \\
\hline $13 \mathrm{a}$ & \multirow{5}{*}{ Documento } & Edición(s) & - \\
\hline $13 b$ & & Outras mencións de responsabilidade & - \\
\hline $13 \mathrm{c}$ & & Identificador(es) & - \\
\hline $13 d$ & & Contido & - \\
\hline $13 \mathrm{e}$ & & Recensións & - \\
\hline
\end{tabular}

${ }^{10}$ Para facilitar a identificación dos campos na descrición que ofrezo no apartado seguinte, asigno un número a cada un e identifico cunha letra as seccións do campo DOCUMENTO. 
4.2.2. Coa finalidade de dar unha idea dos distintos elementos de información que conteñen as RB de BILEGA, ofrezo a continuación unha descrición do contido de cada campo e sección de campo (prescindindo necesariamente de moitos detalles que a farían excesivamente longa):

a) O campo 1 garda o número de orde que asigna o xestor da base de datos a cada novo rexistro. Dado que este número se mantén sempre asociado á mesma RB á que se asignou inicialmente, a súa utilización nas buscas resulta útil sobre todo cando se quere obter información sobre o grupo de rexistros creados desde a última vez que o usuario consultou BILEGA; o único que se precisa é levar conta de cal era o último rexistro da base de datos a derradeira vez que se accedeu a ela (información que se obtén simplemente facendo unha busca con todas as ventás do formulario de buscas baleiras).

b) $\mathrm{O}$ contido dos campos 2, 3 e 4 resulta transparente. Unicamente é preciso indicar que o título que se almacena no campo 2 é o da primeira edición que se cita na sección 13a; cando ese título sufriu algunha modificación en edicións posteriores, aparece citado nesta sección. $\mathrm{O}$ ano de publicación do campo 4 é o correspondente á primeira edición citada en 13a (normalmente tamén a primeira desde e punto de vista editorial) ou o ano de presentación no caso de traballos académicos.

c) $\mathrm{O}$ campo 5 identifica o(s) tema(s) tratado(s) na RB (ata un máximo de cinco). A clasificación realízase a partir do tesauro de temas, constituído por 356 entradas organizadas xerarquicamente nun máximo de sete niveis inclusivos que tratan de cubrir todas as áreas dos estudios lingüísticos. Cada entrada está constituída por unha cadea alfanumérica e un texto que identifica unha disciplina lingüística (fonoloxía, gramática, lingüística histórica, psicolingüística, etc.), un tipo de traballo (notas biobibliográficas sobre lingüistas e filólogos, diccionarios monolingües, traballos onomasiolóxicos, estudios sobre falas, etc.), un concepto teórico (adxectivo, complemento directo, neoloxismos, interferencias, etc.) ou unha variedade non xeográfica (o galego dos textos literarios e paraliterarios, as xergas, etc.). O nivel máis alto deste tesauro está constituído polas seguintes entradas:

1 TRABALLOS XERAIS E OBRAS DE CONSULTA (inclúe, entre outros, os traballos de información bibliográfica, as obras xerais de consulta e os estudios de historiografía da lingüística galega).

2 FONETICA E FONOLOXIA

3 MORFOLOXIA, SINTAXE E ANALISE DO DISCURSO

4 LEXICOLOXIA E LEXICOGRAFIA. ONOMASTICA. APLICACIONS INFORMATICAS

5 DIALECTOLOXIA, XEOLINGÜISTICA, SOCIOLINGÜISTICA E ETNOLINGÜISTICA

6 LINGÜISTICA HISTORICA

7 PSICOLINGÜISTICA E NEUROLINGÜISTICA 


\section{DIDACTICA DO GALEGO}

\section{ESTUDIOS COMPARATIVOS, CONTRASTIVOS E TRADUCCION}

\section{A TRABALLOS SOBRE VARIEDADES NON XEOGRAFICAS DO GALEGO}

d) O campo 6 identifica o(s) enfoque(s) metodolóxico(s) adoptado(s) no traballo: sincrónico (S), diacrónico (D), ambos os dous (DS) ou ningún.

e) O campo 7 identifica o(s) período(s) da historia do galego estudiado(s) no traballo: prerromances $(\mathrm{P})$, galego-portugués $(\mathrm{M})$, galego medio $(\mathrm{E})$ e/ou galego moderno $(\mathrm{C})$.

f) O campo 8 identifica a variedade de lingua estudiada (diatópica / diastrática / diafásica / linguaxe literaria). Tamén aquí se fai a clasificación das RB a partir dun tesauro constituído por 25 entradas organizadas xerarquicamente en catro niveis inclusivos.

g) O campo 9 serve para clasificar os traballos segundo as linguas de que se ocupan. A clasificación das RB tamén se basea nun tesauro de ámbitos constituído por sete entradas organizadas xerarquicamente en tres niveis inclusivos. Dada a concepción ampla da lingüística galega con que traballamos (véxase o apartado 4.3.b.1), pareceunos relevante introducir este parámetro, sobre todo para ofrecer a posibilidade de restrinxir as buscas aos traballos máis centrados no galego. En relación con isto, é preciso advertir que o que chamamos 'ámbito galego' se aplica non só aos traballos centrados no galego medio ou no galego moderno, senón tamén aos que estudian o galego-portugués, sempre que non analicen tamén períodos posteriores da historia do portugués (pois neste último caso asígnaselles o 'ámbito portugués'). Evidentemente, trátase dunha diferenciación conceptual pouco ortodoxa que só encontra xustificación no feito de que BILEGA fose concibida como unha bibliografía da lingua galega e non das linguas galega e portuguesa e, como tal, trate de facilitar da forma máis directa posible a localización das RB pertencentes á lingüística/filoloxía galega no sentido máis estricto. Deste xeito, mentres que para un usuario que desexe obter información sobre RB centradas no galego abonda con que introduza o valor 111 na ventá correspondente a este campo, quen desexe información sobre as RB centradas no portugués deberá combinar nesa ventá os valores 111 e 112 unidos polo operador de disxunción $(111,112)$.

h) O campo 10 clasifica as RB en dous grupos: investigación (I) e divulgación/opinión (D). A fronteira entre os dous tipos non resulta fácil de tracexar porque está lonxe de ser nidia; sen embargo, dada a moi diversa extensión e profundidade das RB incluídas en BILEGA, xulgamos útil ofrecer esta clasificación, sobre todo para que os investigadores poidan discriminar os traballos máis relevantes sobre un tema.

i) O campo 11 almacena a data en que se creou ou se modificou por última vez o rexistro. Esta información resulta útil sobre todo cando se queren limitar as buscas aos rexistros novos ou modificados desde o derradeiro acceso á base de datos. 
k) O campo 12 identifica a lingua en que foi escrita a primeira edición da RB (que será a que apareza en primeiro lugar na sección 13a). Nunha futura versión nova de BILEGA tamén servirá para identificar as traduccións a outras linguas.

1) O campo 13 é un campo de texto organizado en varias seccións:

1.1) A sección 13a resérvase para os datos bibliográficos de edición. O nivel de detalle dos mesmos sitúase a medio camiño entre o dunha ficha catalográfica e a forma habitual de cita nos traballos do noso ámbito científico, é dicir, non chega ao grao de detalle da primeira, pero inclúe elementos de información que normalmente non aparecen nos segundos (por exemplo, tratamos de incluír sistematicamente o número de páxinas das monografías, se conteñen mapas, ilustracións ou fotos e o nome da colección ou serie á que pertencen). En calquera caso, tratamos de deseñar un sistema de cita que resultase o máis transparente posible para un usuario sen un coñecemento específico de biblioteconomía e, sobre todo, que fose formalmente idéntico para todas as RB que conforman a base de datos. Xulgamos que a homoxeneidade formal dos distintos campos e seccións de campo -e sobre todo desta sección, que é a que presenta maior complexidade- era un valor engadido que tiñamos que potenciar.

1.2) A sección 13 b trata de completar a información do campo 3 acollendo elementos como os seguintes: autores (cando son máis de cinco), redactores (fundamentalmente nas obras lexicográficas), colaboradores, autores de prólogos, traductores, correctores lingüísticos, directores de memorias de licenciatura e de teses de doutoramento, etc.

1.3) A sección 13c identifica lingüistas, filólogos, etnógrafos, institucións, autores de obras literarias ou paraliterarias, obras anónimas (principalmente medievais), textos ou coleccións de textos tabeliónicos, cancioneiros e xéneros principais da lírica medieval que son obxecto de estudio nalgunha $\mathrm{RB}$. Isto fai posible que se poidan localizar RB que analizan, por exemplo, a obra lingüística ou os posicionamentos sociolingüísticos de Frei Martín Sarmiento, a obra lingüística e/ou literaria de Ricardo Carballo Calero, a contribución etnográfico-lingüística de Fermín Bouza Brei, o papel da Real Academia Galega na historia externa do galego ou na historiografía da lingüística galega, algún aspecto lingüístico ou filolóxico-lingüístico do Cancioneiro da Ajuda, das cantigas de amigo, da producción lírica de Airas Nunez, da Demanda do Santo Graal ou do Foro Real de Alfonso X o Sabio.

1.4) A sección $13 \mathrm{~d}$ ofrece unha información sumaria do contido da RB que pode chegar a un máximo duns 1.300 caracteres. Esta información trata de ser sempre o máis homoxénea posible para os diferentes tipos de traballo, pero non sempre corresponde a un resumo. Así, nos traballos etimolóxicos máis 
específicos (é dicir, artigos e non diccionarios ou monografías) tratamos de baleirar nesta sección as formas galegas que estudian ou a que fan referencia, cando se trata de traballos pertencentes a ámbitos lingüísticos diferentes ao galego, coa finalidade de que a través delas se poidan localizar as RB pertinentes; por esta razón, incluíronse nesta sección milleiros de voces do léxico común, formas toponímicas e antroponímicas que poderán utilizarse como valores de busca. Certamente, nunha sección coma esta resulta practicamente imposible conseguir unha homoxeneidade total.

1.5) Por último, a sección 13e está reservada para os datos das recensións e notas de publicación.

Os elementos de información que acabo de describir permiten conformar rexistros como o que presento a continuación a título de $\operatorname{mostra}^{11}$ :

ID:

Título:

Autor:

Ano publicación:

Tema:

Enfoque:

Período:

Variedade lingua:

Ámbito:

Tipo traballo:

Data actualización:

Lingua documento: FR

Documento:

$-\mathrm{S}$

I
4781

Alphonse X - Primeyra Partida: Édition et étude Ferreira, José de Azevedo [ed.]

1979

651 ESCRIPTOLOXIA E ECDOTICA. ESTUDIOS ESPECIFICOS

1311 GALEGO E PORTUGUES

A2 O GALEGO DOS TEXTOS XURIDICO-ADMINISTRATIVOS

-M--

231 LINGUAXE XURIDICO-ADMINISTRATIVA

111 GALEGO

07/05/2002

EDICION(S): Thèse pour le Doctorat de 3e Cycle, Université de Paris XIII, 1979, 3 v. $(158+628$ p.).

I [Public.]: Braga, Instituto Nacional de Investigação Científica, 1980, CXLVI + 610 p. (= Textos de Linguística; 3)

OUTRAS MENCIONS DE RESPONSABILIDADE: Roudil, Jean (dir.)

${ }^{11}$ Esta ficha e as que se inclúen nos apartados seguintes reproducen graficamente a forma en que se presentan as RB de BILEGA na Internet como resultado das buscas. 
IDENTIFICADOR(ES): Alfonso X o Sabio / Partidas CONTIDO: A excelente edición do texto vai precedida dun estudio (p. I-CLVI) no que se describen os distintos manuscritos existentes da Primeira Partida (tanto en gal.-port. como noutras linguas peninsulares) e se realiza unha comparación entre a obra castelá e a traducción gal.-port. O fragmento editado (ms. $\mathrm{n}^{\circ} 2$ do Núcleo Antigo do Arquivo Nacional da Torre do Tombo, en Lisboa) é estudiado desde o punto de vista paleográfico e lingüístico (p. XXXVIII-LXVIII) para ver de establecer se se trata dun texto galego ou portugués; tendo en conta os trazos característicos do galego medieval e os tipicamente portugueses sinalados por Rudolf Rübecamp, Jorge Morais Barbosa e Ramón Lorenzo, o editor chega á conclusión de que o texto é portugués, aínda que está cheo de trazos galegos como a forma 'seir', a conservación de -L- e -N('Adriano, aldeanos, çena, colores'), a palatalización do s- (pronome 'xe, xi'), a alternancia oi/ui ('moy / muy, moyto / muyto'), a alternancia b/v ('aboveda / abobeda'), os casos de metafonía na conxugación ('consiguir, fugir, midir'). A lingua do texto, pois, sufriu influencias galegas, ben a través do copista, ben a través da copia mesma. Indícanse tamén os criterios de transcrición seguidos (p. CXXIV-CXLIV) RECENSIONS: G. Martínez Díez, AHDE, 51, 1981:775-776 I Ramón Lorenzo, Verba, 9, 1982:344347 I Mário Martins, Colóquio/Letras, 72, 1983:106107

\subsection{O contido da base de datos}

Como xa indiquei en 4.1, BILEGA é unha base de datos deseñada para o almacenamento de información bibliográfica sobre traballos lingüísticos e filolóxico-lingüísticos que se ocupan -de forma exclusiva ou parcial- da lingua galega en calquera das fases do seu desenvolvemento histórico (incluído o período de formación). A estes traballos engádense aínda outros procedentes de campos como a etnografía, a antropoloxía, as ciencias naturais e a xeografía, que aportan información útil para a investigación do léxico común ou toponímico do galego.

Tomando en consideración os tipos de documento dos que é posible gardar información nun repertorio bibliográfico, BILEGA contén asentos bibliográficos que corresponden a: 
- Monografías publicadas ou partes de monografías (no caso de teren distinta autoría).

- Traballos académicos publicados ou inéditos (fundamentalmente memorias de licenciatura e teses de doutoramento ou traballos equivalentes noutros países).

- Artigos e notas publicados en revistas de investigación ou de divulgación.

- Relatorios e comunicacións presentados en reunións científicas e que apareceron publicados nas actas correspondentes.

- Contribucións a homenaxes e misceláneas.

- Entradas dalgunhas enciclopedias e diccionarios temáticos, como o Dicionário da Literatura Medieval Galega e Portuguesa (Lanciani / Tavani 1993).

- Artigos de xornal (se despois da súa primeira publicación foron reeditados en libro).

- Traballos inéditos de especial interese desde o punto de vista historiográfico ou de especial relevancia na actual investigación do galego.

- Recensións e notas de publicación de calquera dos traballos incluídos como rexistros na base de datos.

Atendendo ao tipo de soporte, como é lóxico son maioritarios os asentos bibliográficos de traballos impresos; pero tamén se poden atopar asentos que remiten a traballos publicados noutros soportes (microfichas, disquetes, CD-ROM). E, neste momento, estamos tratando de fixar os criterios segundo os cales daremos entrada a publicacións electrónicas difundidas pola rede. Non son moitas aínda as que teñen por obxecto o galego, pero o certo é que existen xa algunhas (entre elas, algunha revista, actas de congresos e homenaxes) e é previsible o aumento no futuro deste tipo de publicacións.

Verbo do contido de BILEGA, tamén cómpre facer referencia a algunhas cuestións problemáticas na delimitación do seu ámbito de competencia, aspecto que no apartado 1 xulgabamos relevante para o deseño dunha bibliografía especializada. No caso dunha bibliografía dedicada aos estudios lingüísticos sobre o galego hai, polo menos, dúas cuestións coas que é preciso enfrontarse:

a) A delimitación entre a investigación lingüística e a investigación literaria. Como é ben sabido, hai un campo tradicional dos estudios humanísticos en que conflúen de forma natural aínda hoxe os dous ámbitos de investigación; refírome á Filoloxía, que na cultura occidental ten a respectable antigüidade de 2.300 anos e que, en realidade, foi o berce a partir do cal se desenvolverían os estudios lingüísticos e literarios como especialidades modernas. Esa é a razón de que os dous ámbitos estivesen tan estreitamente unidos durante moitos séculos. Cando, por prurito de máxima exhaustividade, se trata de incorporar a unha bibliografía como BILEGA as RB de todos aqueles traballos que, pertencendo ao ambito da análise literaria, ofrecen algunha consideración lingüística sobre a obra ou obras que estudian, acábase descubrindo o límite difuso que existe entre 
os dous ámbitos e a dúbida entre o que debe e non debe entrar na bibliografía instálase de forma permanente na persoa ou persoas que teñen que tomar a decisión. A proba está en que os criterios aplicados en BILEGA cambiaron en máis dunha ocasión verbo deste aspecto. A norma que seguimos actualmente -sendo conscientes de que sempre atoparemos casos problemáticos- é a de incluír calquera traballo que ofreza algunha consideración lingüística, por moi pequena que sexa. Unha mostra é a que se recolle na seguinte ficha:

\begin{tabular}{|c|c|}
\hline ID: & 8564 \\
\hline Título: & $\begin{array}{l}\text { “"Estuj', 'maeta', 'cofre': su alusividad en las literaturas } \\
\text { románicas" }\end{array}$ \\
\hline Autor: & Juárez Blanquer, Aurora \\
\hline Ano publicación: & 1989 \\
\hline \multirow[t]{3}{*}{ Tema: } & $\begin{array}{l}4171 \text { NOTAS SOBRE O LEXICO DAS OBRAS LITE- } \\
\text { RARIAS OU PARALITERARIAS }\end{array}$ \\
\hline & 4127 EUFEMISMOS E DISFEMISMOS \\
\hline & $\begin{array}{l}\text { A1 O GALEGO DOS TEXTOS LITERARIOS E } \\
\text { PARALITERARIOS }\end{array}$ \\
\hline Enfoque: & $-\mathrm{S}$ \\
\hline Período: & $-\mathrm{M}--$ \\
\hline Variedade lingua: & 4 LINGUAXE LITERARIA \\
\hline Ámbito: & 111 GALEGO \\
\hline Tipo traballo: & I \\
\hline Data actualización: & $23 / 05 / 2000$ \\
\hline Lingua documento: & $\mathrm{CA}$ \\
\hline \multirow[t]{3}{*}{ Documento: } & $\begin{array}{l}\text { EDICION(S): Estudios Románicos, } 4 \text { [= Homenaje al } \\
\text { Profesor Luis Rubio, I], 1987-89:665-675 }\end{array}$ \\
\hline & $\begin{array}{l}\text { IDENTIFICADOR(ES): Pero da Ponte / Johan Garcia } \\
\text { de Guilhade / Cantigas de escarnio }\end{array}$ \\
\hline & $\begin{array}{l}\text { CONTIDO: Polo que atinxe á literatura galega } \\
\text { medieval (estudiada nas p. 672-673), analízase o fun- } \\
\text { cionamento da voz 'maeta' "valija, saco de viaje» } \\
\text { como eufemismo por 'vaxina' nas composicións satí- } \\
\text { ricas. Concretamente, na cantiga B } 1642 \text { / V } 1176 \\
\text { (Inc.: 'Maria Peres, a nossa cruzada') de Pero da } \\
\text { Ponte, onde o eufemismo aparece apoiado polo } \\
\text { adxectivo 'maeta ferrada', o substantivo 'cadeado' e } \\
\text { a expresión 'andou descadeada' }\end{array}$ \\
\hline
\end{tabular}

Noutros casos, aínda que o traballo se poida considerar fundamentalmente literario, non deberían existir dúbidas acerca da súa pertinencia tamén desde o 
punto de vista da investigación lingüística. Entre os moitos exemplos que sería posible seleccionar, pode ilustrar esta consideración a seguinte opinión recente de Clarinda de Azevedo Maia:

$\mathrm{Na}$ análise e estudo da documentação literária ocupa lugar de especial relevo a produção poética pelas informações que, através das rimas e da métrica, fornece para o estudo da história da língua. Se nos fixarmos no período medieval da história da língua portuguesa, o estudo da métrica trovadoresca [...] é de grande interesse para o conhecimento de aspectos fónicos da língua, nomeadamente o tratamento das situações de hiato e da cronologia dos diferentes processos de resolução, assim como dos encontros vocálicos interverbais, da elisão e sua cronologia. (Maia 2002: 241-242)

A aplicación desta consideración atopámola no rexistro de BILEGA recollido na ficha seguinte:

ID:

Título:

Autor:

Ano publicación:

Tema:
10192

As rimas da poesia trovadoresca galego-portuguesa: catálogo e análise

Montero Santalla, José-Martín

2000

651 ESCRIPTOLOXIA E ECDOTICA. ESTUDIOS ESPECIFICOS

641 HISTORIA INTERNA. CAMBIOS

FONÉTICOS E FONOLOXICOS

21 FONETICA E FONOLOXIA. AS VOCAIS

A1 O GALEGO DOS TEXTOS LITERARIOS E PARALITERARIOS

Enfoque: $\quad$ SD

Período: -M--

Variedade lingua: 4 LINGUAXE LITERARIA

Ámbito:

111 GALEGO

Tipo traballo:

I

Data actualización: 20/12/2002

Lingua documento: PT

Documento: $\quad$ EDICION(S): Tese de Doutoramento em Filologia Hispânica (Sec. Galego-Portuguesa), Universidade da Coruña, Facultade de Filologia, Departamento de Galego-Português, Francês e Linguística, Área de Filologias Galega e Portuguesa, 2000, 3 v. (1, p. 1600; 2, p. 601-1200; 3, p. 1201-1796). I [Publics. parciais]: "Sobre o catálogo das rimas trovadorescas" 
(2001, vid.); "Existe rima de vogal aberta com vogal fechada na poesia trovadoresca galego-portuguesa?" (2002, vid.)

OUTRAS MENCIONS DE RESPONSABILIDADE: Martínez Pereiro, Carlos Paulo (dir.)

IDENTIFICADOR(ES): Cancioneiros medievais / Alfonso X o Sabio / Cantigas de Santa María CONTIDO: Catalogación e análise sistemática das rimas das aproximadamente 2.100 cantigas (420 relixiosas e 1.680 profanas) e estudio das implicacións do mecanismo da rima no proceso de creación poética dos trobadores. Ofrece listaxes exhaustivas das rimas e das palabras rimantes e a presentación dos diversos procedementos poéticos baseados na súa distribución nunha mesma cantiga. $\mathrm{O}$ autor trata de sacar partido do estudio da rima, convencido de que pode axudar a defini-lo estado da lingua nos sécs. XIII-XIV e a cronoloxía dalgúns fenómenos (por ex., o timbre das vocais de grao medio e os cambios metafónicos). Organizado en cinco caps.: o $1^{\circ}$ ofrece unha visión xeral da poesía trobadoresca; o $2^{\circ}$ revisa tódalas cantigas do corpus para determina-las rimas e as palabras rimantes (isto só nas cantigas profanas), incluíndo observacións textuais e propostas de modificación de lecturas divulgadas; o $3^{\circ}$ ofrece o catálogo das rimas, distribuídas en dous grupos (consonantes -a maioría- e asonantes); o $4^{\circ}$ estudia as rimas en conxunto, ofrecendo algunhas deduccións lingüísticas e literarias, estatísticas de frecuencia, etc. e discutindo a suposta existencia de rima de vocais abertas con pechadas e de orais con nasais; o $5^{\circ}$ é a listaxe alfabética completa das palabras rimantes

b) Tamén resulta problemática a delimitación do concepto de lingüística galega, alomenos en dous aspectos:

b.1) A vocación de exhaustividade de BILEGA levounos a traballar cun concepto máis ben amplo de lingüística galega, de tal xeito que decidimos incluír estudios que, malia estaren centrados na análise doutras linguas (castelán, portugués, as linguas románicas en conxunto, etc.) ou nalgún aspecto da teoría linguiística, ofrecían datos do galego. Ben é certo que eses datos consisten ás veces en simples referencias ou nunha mínima comparación e/ou contraste e, polo tanto, a contribución destes estudios ao coñecemento do galego xeralmente é moi pouco relevante; pero aínda así pensamos 
que debían estar presentes en BILEGA, sobre todo se ofreciamos a posibilidade de diferencialos a través dos valores dun campo da base de datos (para estes casos, o campo AMBITO) ou da información sobre o contido da RB. Hai mesmo traballos deste tipo encadrados en certos campos da investigación filolóxico-lingüística que, por moi poucos datos do galego que ofrezan, poden aportar elementos interesantes de cara a unha investigación máis centrada nesta lingua; é o caso dos estudios etimolóxicos de ámbito románico ou iberorrománico: algunha figura sobranceira neste campo, como Yakov Malkiel -habitualmente moi pouco citado noutras fontes de información sobre o galego-, ten unha presencia notable en BILEGA, pois nos seus traballos mostra un coñecemento actualizado e de primeira man das fontes bibliográficas de que toma as formas galegas ou galego-portuguesas que cita en moitos dos traballos que conforman a súa inxente producción científica (aínda que a referencia a formas do galego moderno nalgúns deses estudios sexa mínima). Outro tanto se podería dicir dos traballos etimolóxicos que Vicente García de Diego dedicou ao castelán e ás linguas hispánicas en conxunto, ou das contribucións non centradas no galego-portugués de romanistas alemáns como Harri Meier (e algúns dos seus discípulos en Bonn) ou Joseph M. Piel, ambos os dous ben coñecidos polas súas relevantes contribucións á historia do galego e mais do portugués, sobre todo neste campo dos estudios etimolóxicos.

b.2) O feito de que o galego e o portugués compartan unha fase da súa historia suscita o problema de establecer para os textos medievais a fronteira entre o que debe e non debe incluírse nunha bibliografía sobre o galego. Trátase dunha cuestión moi discutida para a que existen opinións diversas e mesmo enfrontadas tanto na filoloxía galega como na portuguesa; en consecuencia, calquera solución que se adopte non deixará de amosar un certo grao de arbitrariedade, sobre todo se eliximos unha referencia temporal concreta para establecer esa fronteira verbo dun proceso -a diferenciación entre galego e portugués- que non foi puntual, senón gradual. Na monografía que representou o primeiro resultado público de BILEGA explicabamos deste xeito a decisión adoptada:

Para delimita-lo galego-portugués medieval fronte á etapa que chamamos galego dos séculos escuros [na actual versión de BILEGA, galego medio] -delimitación necesaria para determina-los traballos da lingüística portuguesa centrados na lingua medieval que con todo dereito deben formar parte tamén da lingüística galega- tomamos como referencia a data tradicional de 1354 (ano da morte de D. Pedro, Conde de Barcelos). (García Gondar (dir.) 1995: 19).

Esa data -que seguimos a manter na actual versión de BILEGA- debe entenderse como unha referencia aproximada e non como un límite cronolóxico preciso, de tal 
xeito que algúns traballos escritos en territorio portugués e habitualmente datados na segunda metade do século XIV tamén están presentes nas RB de BILEGA. Ademais, o feito de traballarmos unicamente cunha delimitación cronolóxica e non espacial levounos a tratar de incorporar a BILEGA os estudios dedicados aos textos tabeliónicos anteriores a 1354 escritos en territorio portugués, sendo conscientes de que esta decisión obrigaba a realizar un importante esforzo, sobre todo, de busca de traballos de transcrición procedentes da investigación de historiadores portugueses, habitualmente menos citados nas fontes bibliográficas impresas de información filolóxica; esta busca aínda non está concluída no momento actual.

\subsection{Explotación}

Un sistema de buscas que permita aos usuarios introducir simultaneamente valores para todos os campos indexados abre múltiples e potentes posibilidades de interrogación á base de datos, e permite obter os documentos desexados cun moi alto grao de precisión. Non é infrecuente que os catálogos automatizados das bibliotecas restrinxan os formularios de busca a só dúas ou tres ventás, probablemente en previsión do gran número de usuarios que poden querer acceder simultaneamente ao catálogo; en tales casos, o usuario vese obrigado a seleccionar un número máximo de campos igual ao de ventás, co cal se están a limitar as posibilidades reais que ofrece o catálogo. Cantos máis valores de campos distintos se introduzan na busca, máis tempo tardará o sistema en devolver os resultados e isto repercute directamente no tempo de acceso dos demais usuarios.

O número de rexistros de BILEGA é moito menor có de calquera catálogo dunha biblioteca universitaria ou doutra institución de investigación: o volume total dos traballos que conforman a tradición filolóxico-linguiística galega é aínda pequeno se o comparamos coas tradicións de estudio doutras linguas que non sufriron as adversas condicións de existencia do galego; en consecuencia, non hai razón ningunha para que se produzan atrasos importantes no acceso á base de datos e na obtención de resultados. Por iso tomamos a decisión de abrila totalmente permitíndolles aos usuarios introducir valores de busca simultáneos nas ventás correspondentes aos trece campos da súa estructura. Tendo en conta, ademais, que en cada ventá se pode introducir máis dun valor de busca (combinándoos mediante operadores de conxunción, disxunción, etc.), resulta posible deseñar buscas moi específicas que ofrezan uns resultados conformes nun altísimo grao coas expectativas do usuario.

Para amosar esta e outras posibilidades de explotación de BILEGA presentarei nos apartados seguintes algúns exemplos de buscas centradas fundamentalmente na utilización de valores pertencentes aos campos metalingüísticos (sobre todo, aos tesauros de temas, variedades de lingua e ámbitos ) ou ao campo DOCUMENTO. 
4.4.1. Supoñamos que o noso interese se centra nos traballos de dialectoloxía especificados no tesauro do campo TEMA. A estructura desta subsección (véxase en 4.2.2 a ubicación da dialectoloxía dentro da estructura xeral do tesauro), con catro niveis inclusivos, é a seguinte:

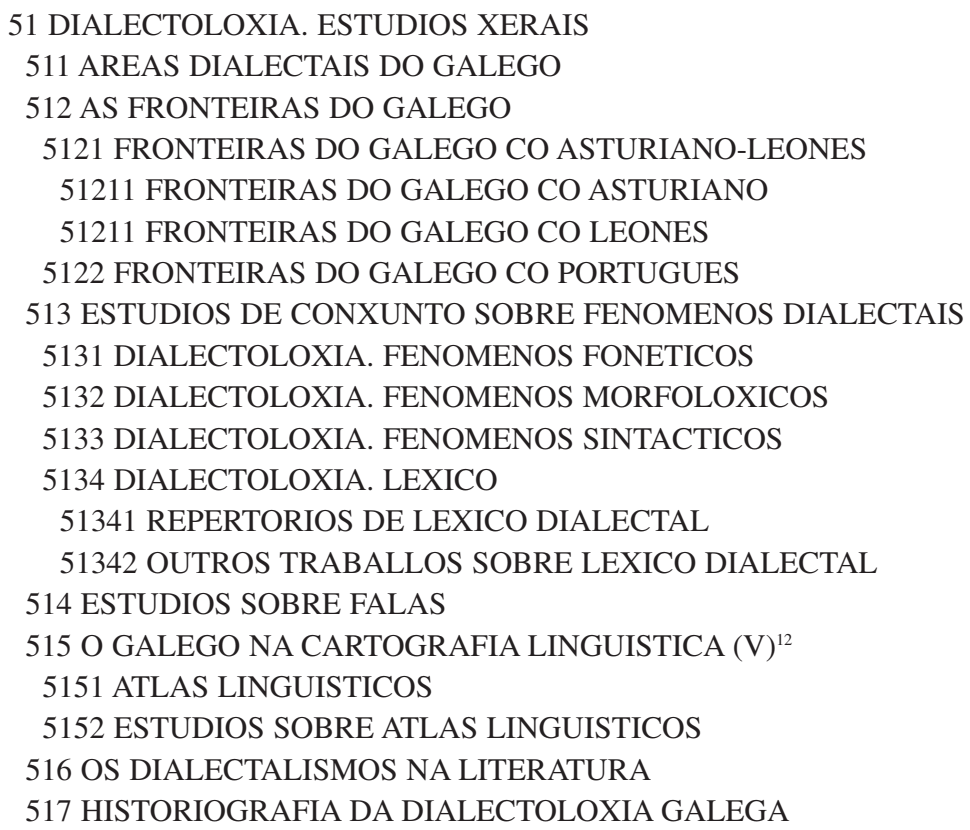

O tipo de busca máis sinxelo é o que opera nun só campo (neste caso, TEMA) mediante a introducción na ventá correspondente dun ou máis valores propios dese campo. Velaquí algunhas das opcións de busca que permite o sistema (semellantes ás que ofrecen outras moitas bases de datos):

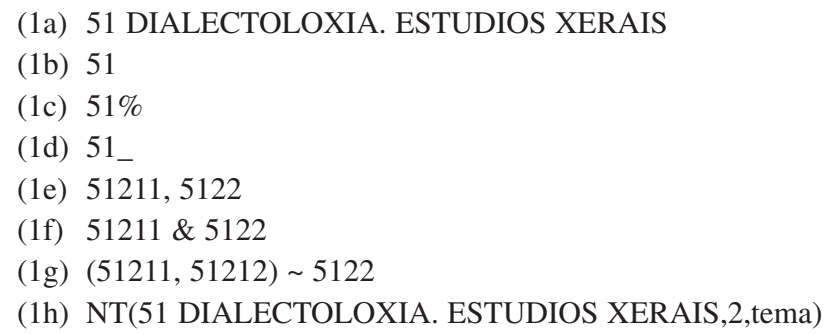

12 A inserción dun (V) a continuación dun tema indica que a súa función é só a de contribuír a configurar unha estructura xerárquica de temas, pero non se asigna a ningún rexistro da base de datos. 
As opcións (1a) e (1b) ofrecen un resultado equivalente: localizan os rexistros que posúen no campo TEMA o valor 51 (por mor da brevidade, omito na descrición dos resultados o texto do tema). A opción (1a) pode introducirse automaticamente seleccionándoa do tesauro; o acceso ao tesauro faise a través dun botón situado á dereita da ventá destinada a introducir os valores de busca para o campo TEMA. O inconveniente da selección automática a partir do tesauro é que só se permite introducir un valor en cada busca. A opción (1b) debe escribila o usuario pero, ademais da súa brevidade (non é preciso escribir o texto do tema para que a busca funcione; abonda con escribir a cadea alfanumérica que precede ao texto), ten a vantaxe de permitir a introducción de varios valores combinados cos operadores axeitados.

A opción (1c) traballa co símbolo do "tanto por cento" (\%), que no sistema funciona como comodín equivalente a unha cadea de caracteres de calquera lonxitude (incluída a cadea de lonxitude cero). Isto significa que con esta instrucción de busca recuperamos todos os rexistros que no campo TEMA conteñan un valor que comece pola cadea 51, é dicir, todos os traballos clasificados como dialectolóxicos na base de datos.

A opción (1d) traballa co símbolo do "guión baixo" (_), que no sistema funciona como comodín equivalente a un carácter calquera. No resultado desta busca, polo tanto, recupéranse os rexistros que conteñan no campo TEMA un valor que empece pola cadea 51 seguida doutro carácter, é dicir, 511, 512, 513, 514, 516 e 517 (lémbrese que o valor 515 está definido como "baleiro", polo que non pode aparecer ningún rexistro que o conteña).

A opción (1e) combina dous valores mediante o operador de disxunción (,), equivalente a un ou lóxico. Como resultado, recupéranse os rexistros que conteñen no campo TEMA polo menos un dos dous valores da busca, é dicir, 51211 ou 5122.

A opción (1f) combina dous valores mediante o operador de conxunción (\&), equivalente a un $e$ lóxico. Como resultado, recupéranse os rexistros que conteñen no campo TEMA os dous valores da busca xuntos, é dicir, os rexistros cos valores 51211 e 5122.

A opción (1g) combina tres valores, agrupando os dous primeiros combinados co operador de disxunción (,) e combinando con eles o terceiro mediante o operador de conxunción negativa $(\sim)$, equivalente a un e non lóxico. Como resultado, recupéranse os rexistros que conteñen no campo TEMA calquera dos valores $51211 \mathrm{ou}$ 51212, pero que non conteñen o valor 5122 .

A opción (1h) traballa co operador NT, que serve para expandir a consulta incluíndo os valores definidos no tesauro como fillos ou de nivel máis baixo có valor especificado. A instrucción hai que interpretala do seguinte xeito: expandir a consulta 
do valor 51 incluíndo o nivel inmediatamente inferior na xerarquía do tesauro TEMA. Isto significa que o sistema recuperará os rexistros que conteñan no campo TEMA algún dos seguintes valores: 51, 511, 512, 513, 514, 516 e 517 (lémbrese que o valor 515 está definido como baleiro).

Os exemplos propostos mostran algunhas das moitas posibilidades que existen para a explotación dun tesauro nas buscas e as vantaxes que unha organización deste tipo ofrece no sentido de permitir que sexa o usuario o que decida desde que nivel de xeneralidade quere construír a súa interrogación á base de datos.

4.4.2. A especificidade das buscas increméntase a partir do momento en que comezamos a combinar valores de busca que corresponden a campos distintos da base de datos. Así, seguindo no campo temático da dialectoloxía, poderiamos estar interesados en recuperar os rexistros que corresponden a $\mathrm{RB}$ de estudios sobre falas do galego occidental. Para iso non temos máis que introducir o valor 514 na ventá do campo TEMA e o valor 11 (que corresponde ao galego occidental no tesauro de variedades de lingua) na ventá do campo VARIEDADE LINGUA. Entre os rexistros que recuperariamos estaría o seguinte:

ID:

Título:

Autor:

Ano publicación:

Tema:

Enfoque:

Período:

Variedade lingua:

Ámbito:

Tipo traballo:

Data actualización:

Lingua documento: $\mathrm{CA}$

Documento:

I
43

El habla de O Grove

Enríquez Salido, María del Carmen

1971

514 ESTUDIOS SOBRE FALAS 427 VOCABULARIOS DIALECTAIS

DS

$---\mathrm{C}$

11 GALEGO OCCIDENTAL

111 GALEGO

23/07/2002

EDICION(S): Tese de Doutoramento, Universidade de Santiago, Facultade de Filosofía e Letras, 1971, 501 p. + [52 p.], mapas, ils. I [Res.]: [Santiago de Compostela], [Universidade de Santiago], 28 p., il. I [Publics.parciais]: Léxico de O Grove (1974, vid.); "Fonética y fonología del gallego de O Grove" (1976, vid.)

OUTRAS MENCIONS DE RESPONSABILIDADE:

García, Constantino (dir.) 
CONTIDO: Exhaustiva monografía dialectal da fala deste concello da provincia de Pontevedra, constituído polas parroquias de San Martiño e San Vicente. Historicamente foi a primeira Tese de Doutoramento de dialectoloxía galega presentada na Universidade de Santiago de Compostela, inaugurando así unha liña de investigación que chega ata hoxe. Ofrece unha descrición fonético-fonolóxica (sincrónica e diacrónica) e morfolóxica e a recolleita do léxico; nesta última combínase a descrición etnolingüística organizada en campos nocionais con listas de vocabulario nas que para cada entrada se dá a transcrición fonética, a clase de palabra, a definición lexicográfica (utilizando como metalingua o castelán) e se indica a parroquia onde se recolleu. A descrición morfolóxica aínda permanece inédita

Como se pode apreciar nesta ficha, o sistema resalta con letra negra os valores dos campos que foran introducidos polo usuario como valores de busca.

4.4.3. Outra posible combinación de valores de dous campos, sen saír do terreo da dialectoloxía, sería a correspondente á seguinte busca: os dialectalismos na obra literaria de Celso Emilio Ferreiro.

Os valores de busca introduciríanse da forma seguinte (indico os campos a que corresponden):

TEMA: 516

DOCUMENTO: Celso Emilio Ferreiro

Entre os rexistros recuperados estaría o da ficha seguinte:

ID:

Título:

Autor:

Ano publicación:

Tema:

Enfoque:

\section{1}

"O dialectalismo en Celso Emilio Ferreiro"

Hermida Gulías, Carme

1992

516 OS DIALECTALISMOS NA LITERATURA

514 ESTUDIOS SOBRE FALAS

A1 O GALEGO DOS TEXTOS LITERARIOS E PARALITERARIOS

-S 


$\begin{array}{ll}\text { Período: } & -- \text { C } \\ \text { Variedade lingua: } & 4 \text { LINGUAXE LITERARIA } \\ \text { Ámbito: } & 111 \text { GALEGO } \\ \text { Tipo traballo: } & \text { I } \\ \text { Data actualización: } & \text { 11/06/1998 } \\ \text { Lingua documento: } & \text { GA } \\ \text { Documento: } & \text { EDICION(S): en Rosario Álvarez Blanco (coord.), } \\ & \text { Estudios dedicados a Celso Emilio Ferreiro, I, Santiago } \\ & \text { de Compostela, Universidade de Santiago, 1992:301- } \\ & 315,4 \text { mapas } \\ & \text { IDENTIFICADOR(ES): Celso Emilio Ferreiro } \\ & \text { CONTIDO: O traballo pretende "comprobar en que } \\ & \text { medida as escollas fonéticas, morfolóxicas e léxicas } \\ & \text { feitas por Celso Emilio Ferreiro nas súas obras res- } \\ & \text { ponden á lingua de Celanova, a súa vila natal, ou o } \\ & \text { que é o mesmo, ó galego do bloque central, subárea } \\ & \text { auriense na que está encadrada Celanova" (p. 301). } \\ & \text { Contén: } 1 . \text { Introducción; } 2 . \text { Fenómenos relevantes } \\ & \text { dialectalmente: 2.1. Fonética; 2.2. Morfoloxía; 2.3. } \\ & \text { Fenómenos léxicos; 3. Conclusión }\end{array}$

4.4.4. Nesta liña de construír buscas moi específicas poderiamos chegar a extremos como o seguinte: recuperar rexistros da autoría de Joseph M. Piel, publicados con anterioridade a 1970, que adopten a perspectiva diacrónica (D), que estudien o galego-portugués (M) e o galego moderno (C), que correspondan a estudios onomásticos (valor alfanumérico 43\%) ou etimolóxicos (valor alfanumérico 6443), que sexan traballos de investigación (I) e nos que se inclúa o estudio dalgunha das seguintes formas: braña, gándara, corgo, trives.

Os valores de busca introducirianse da forma seguinte:

AUTOR: Piel Joseph M

ANO: 1970 (precedido do operador de comparación <)

ENFOQUE: D-

PERIODO: -M-C

TEMA: $43 \%, 6443$

TIPO: I

DOCUMENTO: braña, gándara, corgo, trives

Dous dos rexistros recuperados nesta busca serían os que aparecen nas fichas seguintes: 
ID:

Título:

Autor:

Ano publicación:

Tema:
610

"Nomes de lugar referentes ao relevo e ao aspecto geral do solo (Capítulo de uma toponímia galego-portuguesa)"

Piel, Joseph M.

1947

4311 ESTUDIOS ETIMOLOXICOS SOBRE TOPONIMOS

6443 HISTORIA DO LEXICO. ESTUDIOS ETIMOLOXICOS

622 INFLUENCIAS SUBSTRATISTICAS E SUPERESTRATISTICAS

Enfoque: D-

Período: $\quad$-M-C

Variedade lingua:

Ámbito:

111 GALEGO

Tipo traballo: I

Data actualización: 11/06/1998

Lingua documento: PT

Documento:

EDICION(S): RPF, I/1, 1947:153-198, 2 mapas

CONTIDO: Inclúe os topónimos gal. 'Algara; Val, Valboa, Balboa, Balouta, Valoiro, Baloira, Balga, Valga, Valgote; Barcia, Barciela(s), Barja, Barjiña(s), Barjela, Barjiela(s); Barzamedelle; Barroca(s), Barrocal; Calve, Calveliño, Calvelle, Calvente; Candorca, Candorco; Chainza, Chaira(s), Chan(s), Chao(s), Chas, Chandebrito, Chandevila, Chandorrio, Chaudarcas, Chenlo, Chenzas, Chiela; Colado; Costiña, Costoira(s), Costoura(s); Cotaredo, Cotarel(o); Fondón, Fondós; Fórnea; Gándara, Gandariña, Gandra, Granda, Grandela, Grandachan, Grandameá; Enfesta, Enfestela, Infistela, Infesta; Mambrillas; Mamoalta, Mamoela, Mamuela(s); Montecelo, Montaña; Naballo(s), Navallo(s); Outomouro; Páramo(s), Paraño(s), Paramuiño, Paraimas; Penaedrade, Penagundín, Penido(s), Penela(s); Picouto, Picouso, Picouzo; Requeixo, Requejiño; Sertaiña; Veiga, Veiguiña(s)' e 'Veiguicela'. Contén tamén abundantes referencias a formas medievais 
ID:

Título:

Autor:

Ano publicación:

Tema:
612

"As águas na toponímia galego-portuguesa"

Piel, Joseph M.

1947

4311 ESTUDIOS ETIMOLOXICOS SOBRE TOPONIMOS

6443 HISTORIA DO LEXICO. ESTUDIOS ETIMOLOXICOS

622 INFLUENCIAS SUBSTRATISTICAS E SUPERESTRATISTICAS

Enfoque:

D-

Período:

-M-C

Variedade lingua:

Ámbito:

111 GALEGO

Tipo traballo:

I

Data actualización: 11/06/1998

Lingua documento: $\mathrm{PT}$

Documento:

EDICION(S): BmF, VIII/4, 1947:305-342

CONTIDO: Entre os gal. inclúe 'Agualada, Aguas Mestas; Lamaboa, Lamamá, Lamaforcada,

Lameiroquente, Lamalonga, Lamarredonda, Lamapodre, Lamasaida, Lamansián, Lamartín, Lamasapín,

Lama(r)cide, Lamasgalán, Lamego; Tola, Tollo; Cale(s), Cal do Sapo, Cal do Correlo, Caldovilar, Caldebarcos, Calleiros, Caleiro/-a; Couce, Coucegordo, Coucedaleje, Coucevillar, Coucieiro; Rega(s), Rigueiro, Rigueiras, Regueiriño/-a, Regueiral, Regüela, Regolevado, Regocavado, Regocorto, Regueirofozado, etc.; Pau de Raposo; Trem(e)ado; Moledo; Lavadouro(s), Lavadoiro; Poza Bella, Pozacas; Lodeiro, Lodairo; Peago, Piago, Peaguda, Piegalbo, Piagolongo; Fontao, Fontán, Fontenlo/-a, Fontaiño, Fonteita, Fontecada, Fontegrada, Fontevedra, Fontoira, Fonteiroa, Fontefeal, Fonfría, Fonsagrada, Fongate, etc.; Riobóo, Ribón, Rial, etc.; Rañó, Rañoa, Rañoá, Rañada, Rañadoiro, Rañal, Rañedo, Rañón, Rañestras; Fervenza, Fervedoira, Ferveda, Fervenzedo; Revolt(iña)a, Revolto; Riañ(o)a; Pontig(a)o, Pontevedra, etc.; Lagouzos, Lagazos, etc.; Corgo/-a'

RECENSIONS: Manuel de Paiva Boléo, RPF, II/1-2, 1948:381 
4.4.5. A explotación da información que contén o campo DOCUMENTO aínda ofrece outras posibilidades. Por exemplo, incluímos no resumo de moitas RB correspondentes a artigos que estudian algún aspecto lingüístico ou filolóxico do corpus poético dun trobador medieval ou unha cantiga específica a(s) súa(s) identificación(s), segundo a práctica habitual entre os especialistas de identificar cunha letra maiúscula o cancioneiro en que aparecen, seguida do número de orde que lle corresponde a cada cantiga (ademais do incipit). Isto quere dicir que introducindo unha desas identificacións como valor de busca para o campo DOCUMENTO recuperaremos rexistros en que se analiza esa cantiga (sexa de forma exclusiva ou xunto con outras). Un caso moi axeitado podería ser o da famosa "cantiga da garvaia", atribuída a Pai Soarez de Taveirós e conservada no Cancioneiro da Ajuda (A) co número 38; pois ben, simplemente con escribir A 38 como valor de busca na ventá correspondente ao campo DOCUMENTO recuperaremos unha morea de RB que remiten a traballos dedicados á interpretación desta composición, entre eles o que aparece reflectido na ficha seguinte:

$\begin{array}{ll}\text { ID: } & 4960 \\ \text { Título: } & \text { "Postilla alla 'cantiga da guarvaya", } \\ \text { Autor: } & \text { Pellegrini, Silvio } \\ \text { Ano publicación: } & 1957 \\ \text { Tema: } & 4171 \text { NOTAS SOBRE O LEXICO DAS OBRAS LITE- } \\ & \text { RARIAS OU PARALITERARIAS } \\ & \text { A1 O GALEGO DOS TEXTOS LITERARIOS E } \\ & \text { PARALITERARIOS } \\ \text { Enfoque: } & \text {-S } \\ \text { Período: } & \text {-M-- } \\ \text { Variedade lingua: } & 4 \text { LINGUAXE LITERARIA } \\ \text { Ámbito: } & \text { 111 GALEGO } \\ \text { Tipo traballo: } & \text { I } \\ \text { Data actualización: } & \text { 11/03/2003 } \\ \text { Lingua documento: } & \text { IT } \\ \text { Documento: } & \text { EDICION(S): Filologia Romanza, IV/1, 1957:113-118 } \\ & \text { IDENTIFICADOR(ES): Pai Soarez de Taveirós / } \\ & \text { Cantiga da garvaia / Cantigas de escarnio } \\ & \text { CONTIDO: Sobre a interpretación da cantiga A 38 } \\ & \text { (Inc.: 'No mundo non me sei parella') atribuída ó } \\ & \text { trobador galego Pai Soarez de Taveirós. Proponse } \\ \text { entender 'retraer' (verso 5) como «retratar» e relacio- } & \text { nar 'branca' e 'vermelha' (1ª estrofa) con 'retraer' en } \\ & \text { vez de con 'senhor'. Ademais, o autor considera os } \\ \text { dous adxectivos como unha descrición anticipada da } & \text { 'guarvaya' da 2a estrofa } \\ & \end{array}$




\subsection{Estado actual de BILEGA e posibles melloras}

Como xa sinalei en 4.1, atopámonos neste momento na fase de probas da versión 2.0 de BILEGA que axiña estará operativa en substitución da versión 1.0.2. Non obstante, mentres estivemos a montar esta nova versión, non abandonamos as tarefas de actualización restrospectiva e prospectiva da base de datos, de tal xeito que na data de referencia sinalada na nota 5 contiña 392 rexistros novos respecto da versión que estaba operativa na Internet.

Para dar idea do traballo levado a cabo nos nove anos transcorridos dende o deseño inicial de BILEGA en 1994 quizais abonde con sinalar que a información que contén actualmente ocuparía máis de 3.000 páxinas nun texto impreso de 60 liñas por páxina e 80 caracteres por liña con letra Times New Roman tipo 10. Sen embargo, tamén pode ser ilustrativo ofrecer de forma sucinta algúns datos cuantitativos sobre os elementos que contén:

- $\mathrm{N}^{\circ}$ de rexistros da táboa BILEGA: 11.243.

- $\mathrm{N}^{\mathrm{o}}$ total de asentos bibliográficos: 17.742 (dos que 3.069 corresponden a recensións e notas de publicación).

- $\mathrm{N}^{\mathrm{o}}$ total de rexistros con información do contido: 10.363 (92.17\% do total de rexistros).

- $\mathrm{N}^{\mathrm{o}}$ total de valores de busca: 88.997 .

- $\mathrm{N}^{\mathrm{o}}$ total de valores temáticos: 22.522 (25.30\% do total de valores de busca).

- $\mathrm{N}^{\mathrm{o}}$ total de identificadores: 4.432 .

- $\mathrm{N}^{\mathrm{o}}$ de rexistos da táboa REVISTAS (publicacións periódicas citadas): 798.

Estes datos amosan que a media de valores de busca asignados a cada rexistro está moi próxima a 8 e a de valores temáticos é 2.

Xulgada globalmente, tendo en conta o grao de información que ofrece en cada rexistro e o nivel de exhaustividade acadado (sen deixar de recoñecer que a exhaustividade total é practicamente imposible), penso que non é esaxerado afirmar que BILEGA constitúe, polo de agora, un recurso único no ámbito das linguas hispánicas.

Non obstante, as ferramentas deste tipo son, por definición, sempre mellorables e por esta razón, ademais de continuar co traballo de actualización retrospectiva e prospectiva, estamos a avaliar neste momento a posibilidade de introducir as seguintes modificacións ou novas implementacións que poderían contribuír a facer de BILEGA un recurso aínda máis útil:

a) Reorganización e ampliación do tesauro de temas para ofrecer novas posibilidades de buscas cada vez máis precisas. 
b) Reorganización do tesauro de variedades de lingua co obxectivo de permitir nunha futura versión a inclusión de máis dun valor no campo correspondente.

c) Diferenciación no campo PERÍODO entre as fases prerromances e a galego-portuguesa, que ata agora aparecían agrupadas baixo o valor 'galego-portugués' .

d) Conversión dos tesauros monolingües actuais en tesauros multilingües.

e) Inclusión de traballos publicados na rede.

f) Creación dunha versión de BILEGA en CD-ROM.

Como recurso en liña que trata de ofrecer un servicio de información permanentemente actualizada e de contribuír á presencia do galego na rede, BILEGA é un proxecto aberto que ten vocación de futuro na medida en que se manteñan as condicións que a fixeron viable e mentres sigamos a ter a percepción de que presta realmente ese servicio, como neste momento o testemuñan os cincocentos usuarios de vinte países que ten rexistrados.

\section{Referencias Bibliográficas}

BL 1978 = Comité International Permanent des Linguistes (1978): Bibliographie linguistique de l'année 1975 et complément des années précédentes $=$ Linguistic Bibliography for the Year 1975 and Supplement for Previous Years (Utrecht I Anvers: Spectrum).

BL 1989 = Comité International Permanent des Linguistes (1989): Bibliographie linguistique de l'année 1987 et complément des années précédentes = Linguistic Bibliography for the Year 1987 and Supplement for Previous Years (Dordrecht / Boston / London: Kluwer).

Cepeda, I. Vilares (1995): Bibliografia da Prosa Medieval em Língua Portuguesa: Subsídios (Lisboa: Ministério da Cultura, Instituto da Biblioteca Nacional e do Livro).

Freire, José Luis (1988) : “Galician”, Comparative Romance Linguistics Newsletter, 37/2: 80-87.

García Gondar, F. (dir.) (1995): Repertorio bibliográfico da lingüística galega: Desde os seus inicios ata 1994 inclusive (Santiago de Compostela: Centro de Investigacións Lingüísticas e Literarias Ramón Piñeiro).

Herrero Valeiro, Mário J. (1993): Aproximação à análise do discurso sociolinguístico sobre o caso galego (Memoria de Licenciatura, Universidade da Coruña, Facultade de Humanidades, inédita).

Lanciani, G. / Tavani; G. (coords.) (1993): Dicionário da Literatura Medieval Galega e Portuguesa (Lisboa: Caminho). 
Maia, C. de Azevedo (2002): "Dos textos escritos à história da língua", en Head, B. F. / Teixeira, J. / Lemos, A. Sampaio / Barros, A. Leal de / Pereira, A. (orgs.): História da Língua e História da Gramática: Actas do Encontro: 231-249 (Braga: Universidade do Minho, Instituto de Estudos Humanísticos).

RB 1957 = Kuhn, A. (ed.) (1957): Bibliographie, 1940-1950 (Tübingen: Max Niemeyer).

Regueira Fernández, X. L. (coord.) (1996): Guía bibliográfica de lingüística galega (Vigo: Xerais). 